\section{BMJ Global Health}

\title{
Social capital in the prevention and management of non-communicable diseases among migrants and refugees: a systematic review and meta- ethnography
}

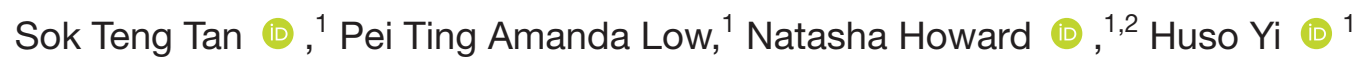

\begin{abstract}
To cite: Tan ST, Low PTA, Howard N, et al. Social capital in the prevention and management of non-communicable diseases among migrants and refugees: a systematic review and metaethnography. BMJ Global Health 2021;6:e006828. doi:10.1136/ bmjgh-2021-006828
\end{abstract}

Handling editor Stephanie M Topp

Received 7 July 2021 Accepted 5 December 2021
D) Check for updates

(C) Author(s) (or their employer(s)) 2021. Re-use permitted under CC BY-NC. No commercial re-use. See rights and permissions. Published by BMJ.

${ }^{1}$ Saw Swee Hock School of Public Health, National University of Singapore and National University Health System, Singapore ${ }^{2}$ Department of Global Health and Development, London School of Hygiene and Tropical Medicine, London, UK

Correspondence to

Dr Huso Yi; ephyh@nus.edu.sg

\section{ABSTRACT}

Globally, the burden of non-communicable diseases (NCDs) falls disproportionately on underserved populations. Migrants and refugees are particularly vulnerable due to economic instability and systemic poverty. Despite the myriad of health risks faced by migrants and refugees, access to appropriate healthcare is hindered by structural, cultural and socioeconomic barriers. We conducted a systematic review and meta-ethnography to obtain critical insight into how the interplay of social capital and structural factors (eg, state policies and socioeconomic disadvantage) influences the prevention and treatment of NCDs in migrant and refugee populations. We included 26 studies of 14794 identified articles, which reported qualitative findings on the structure and functions of social capital in NCD prevention and management among migrants and refugees. We synthesised findings, using the process outlined by Noblit and Hare, which indicated that migrants and refugees experienced weakened social networks in postmigration settings. They faced multiple barriers in healthcare access and difficulty navigating healthcare systems perceived as complex. Family as the core of social capital appeared of mixed value in their NCD prevention and management, interacting with cultural dissonance and economic stress. Community organisations were integral in brokering healthcare access, especially for information diffusion and logistics. Healthcare providers, especially general practitioners were important bridges providing service-user education and ensuring a full continuum of quality care. While social capital reduced immediate barriers in healthcare access for NCD prevention and management, it was insufficient to address structural barriers. System-level interventions appear necessary to achieve equitable healthcare access in host countries. PROSPERO registration number: CCRD42020167846.

\section{INTRODUCTION}

Increasingly exclusionary social and health policies deprive low-wage migrants (hereafter 'migrants') and refugees/refugee-like migrants (hereafter 'refugees') of resources

\section{Key questions}

What is already known?

- Social capital can develop protective networks and facilitate healthcare access

- It alleviates the negative impacts of socioeconomic disadvantages on health.

- These findings were not conclusive, and effects were not consistently desirable.

What are the new findings?

- Social capital is converted into practical resources, which were integral in improving health literacy, increasing access to appropriate healthcare and adhering to prescribed treatment and selfmanagement of non-communicable diseases (NCDs) among migrants and refugees.

- Successful conversion of social capital into effective NCD prevention and management depend on the interactions of individual circumstances, community dynamics and wider systemic and structural issues in the populations.

- Healthcare provider's cultural competency is crucial as linking capital to empower migrants and refugees to act on the health information received.

What do the new findings imply?

- Social capital can alleviate some healthcare access barriers among migrants and refugees.

- Structural forces and institutional actors are significant in building social capital among migrants and refugees.

- There is a need to enhance healthcare providers cultural competency and encourage patient-centred communication between providers and migrants and refugees.

and opportunities for social mobility and quality healthcare. ${ }^{1}$ Migrants move across borders in search of better economic opportunities. Asylum-seekers and refugees lose or are forced to leave their financial capital behind during flight. On arrival in destination 
or transit countries, their human capital—knowledge and skills-is mostly unappreciated or unrecognised; social capital then becomes essential to building other capital.

Migrants and refugees experience a high burden of infectious, non-communicable and psychiatric diseases. ${ }^{2}$ Quality healthcare access is underpinned by the degree of a health system's availability, accessibility, accommodation, affordability and acceptability in meeting the population's abilities to perceive, to seek, to reach, to pay for and engage with the systems. ${ }^{34}$ The dissonance between these populations and transit or host health systems is manifested through multiple structural, physical, financial, sociocultural and communicative barriers in healthcare access. ${ }^{5-8}$ Lack of health literacy compromises their efficacy in navigating health systems. ${ }^{9}$ This is exacerbated by their lack of legal status, especially when inclusive health policies and socialeconomic protection (eg, social safety net) are absent. ${ }^{10}$ While many states have to navigate difficult legal and humanitarian imperatives in hosting and accepting forced migrants, including refugees and asylum seekers, it is important to note the moral imperative of universal healthcare access for those in need. ${ }^{11}$ Inclusive health policies require an effective translation of rights-based principles into accountable governance and concrete actions. ${ }^{12}$ Consequently, and owing largely to socially exclusionist policies, health systems may struggle to address unmet health needs among migrants and refugees. ${ }^{13} 14$ This is especially challenging when long-term treatments are required.

Non-communicable diseases (NCDs) are diseases that do not transmit from one person to another. In this paper, we use the WHO definition 'NCDs, known as chronic diseases, tend to be of long duration and are the result of a combination of genetic, physiological, environmental and behavioural factors.' The four main types of NCDs are cardiovascular diseases, cancers, chronic respiratory diseases and diabetes, and they require lifetime care. ${ }^{15}$

Health disparities among disadvantaged populations are evident with NCDs. ${ }^{16}$ Compared with host populations, higher NCD prevalence rates were found in migrants, ${ }^{17}$ and refugees in West Asia ${ }^{18-22}$ and Southeast Asia. ${ }^{18}$ Despite their unmet needs, state policies lack inclusivity to tailor health services to these populations. This results in low NCD-related health literacy, barriers to health service utilisation, including timely screening, effective treatment and self-management. ${ }^{23}{ }^{24}$ As a consequence, complications arise and cause catastrophic medical costs and lives lost. ${ }^{25}$ Improving NCD prevention and management among migrants and refugees requires dissecting their complex yet unique circumstances to address the intersection of cultural identity, legal and immigration status, socioeconomic status, and the wider sociopolitical environments that underlie the unequal distributions of resources and capability in health. ${ }^{162627}$

\section{Social capital and migrant health}

People mobilise personal, community and institutional resources to achieve various purposes. Social capital is a collection of resources derived from social connections and networks. ${ }^{28}$ Portes summarised that social capital could be categorised into value introjection, bounded solidarity, reciprocity exchanges and enforceable trusts depending on the motivations of those who make social resources available. ${ }^{29}$ Social capital is formed, maintained and enhanced based on three types of social networks: bonding, bridging and linking. ${ }^{28}$ Bonding capital refers to resources drawn from strong ties within close kinship. Networks formed across heterogeneous groups provide bridging capital. Linking capital connects networks across vertical hierarchies. Resources mediated by these networks enable both emotional and material social support, information diffusion, education and job opportunities, and other benefits derived from collective efforts. ${ }^{28}{ }^{29}$ Bonding capital is thus essential for people to 'get by' in daily life, while weak ties such as bridging capital facilitate 'getting ahead' through more effective information diffusion, for example, access to economic opportunities outside of close kinship. ${ }^{28} 3031$

The consequences brought by social capital vary among migrants and refugees. Membership in a close-bonding community often requires norm conformity, which exerts strong social control and restricts individual autonomy and liberty. ${ }^{29}$ Similarly, social contagions of undesirable behaviours could bring about adverse social and health outcomes within close-knit communities if links to an external support system are absent. ${ }^{32}$ Isolation from the wider community is common among migrants and refugees in host countries due to physical separation, stigmatisation and discrimination. This can reinforce social disadvantages and lead to poorer health. ${ }^{33}$

Social capital is instrumental in developing protective networks and facilitating healthcare access. ${ }^{34}$ Specifically, it alleviates the negative health impacts of socioeconomic disadvantages among marginalised populations. ${ }^{35}$ Quantitative studies reported positive effects of social capital on hypertension detection, ${ }^{36}$ better control of diabetes ${ }^{37-39}$ and cardiovascular disease risks. ${ }^{38}$ However, such findings are not conclusive. ${ }^{39}{ }^{40}$ In a review of the negative health effects of social capital, strong bonding was found to facilitate the spread of high-risk behaviours among network participants. ${ }^{32}$ In order to obtain holistic insights on these quantitative findings, ${ }^{35-39}$ it is crucial to understand contextual effects of social capital on NCD prevention and management. In this paper, we aim to determine how social capital is organised, mobilised and used in NCD prevention and treatment among migrants and refugees using a meta-ethnography. ${ }^{41}$

\section{METHODS}

\section{Operationalisation and categorisation of migrants}

We focused on populations characterised by international migration, including migrants, refugees and asylumseekers. The terms 'migrant' and 'refugee' encompass diversity and sometimes cause confusion. For example, a 'migrant' is generally understood as transient and 
an 'immigrant' as permanent but this is not yet widely accepted. ${ }^{42}$ Similarly, the 1951 Convention Relating to the Status of Refugees provides definitions for 'refugee' and 'asylum-seeker, ${ }^{43}$ yet many authors still use them interchangeably. Despite such references, migration situations are complex and often contextual. Transient migrants might extend their stay in host country permanently without legal residency. ${ }^{44}$ A refugee recognised by the host country legal system is fundamentally different from a mandate refugee recognised by the United Nations High Commissioner for Refugees ${ }^{46}$ in a country that has no legal definition or recognition of refugee status. ${ }^{57}$ Although these groups carry the same labels, actual experiences and needs differ due to specific juridico-political contexts.

In this paper, we adapted the International Organisation for Migration's definition of a migrant as '... a person who moves into a country other than that of his or her nationality or usual residence, so that the country of destination effectively becomes his or her new country of usual residence. ${ }^{42}$ We further narrowed the inclusion to only migrants who are economically disadvantaged. Although 'refugee' is legally defined, ${ }^{43}$ the context and their legal status in host countries influence the treatments they receive. We included resettled refugees (refugees who were transferred from a transit country to another country that has agreed to admit them), mandate refugees (refugees defined by the 1951 Convention, regardless of whether the host country has ratified it) and asylum-seekers (individuals who are waiting for their asylum status to be assessed). Table 1 shows a summary of migration categories used in the review.

\section{Database searches}

We conducted a systematic review and meta-ethnography of academic literature reporting qualitative primary findings on migrant and refugee social capital and NCDs. The first and second authors searched seven academic databases systematically (ie, PubMed, Embase, PsycINFO, CINAHL, Scopus, EBSCOHost, Web of Science). The full search strings for all databases are included as online supplemental file 1 . We combined search terms

\begin{tabular}{ll}
\hline Table 1 & Migration categories used in this review \\
\hline Term & Categories \\
\hline Migrant & $\begin{array}{l}\text { Low-wage migrant, low-skilled migrant, migrant or } \\
\text { immigrant who lives in poverty, transient migrant, } \\
\text { seasonal migrant worker, undocumented migrant, } \\
\text { trafficking victim. }\end{array}$ \\
Refugee & $\begin{array}{l}\text { Resettled refugee, mandate refugee, refugee in } \\
\text { transit. }\end{array}$ \\
Asylum- & $\begin{array}{l}\text { Individual who is waiting for their asylum claim to be } \\
\text { seeker* }\end{array}$ \\
\hline
\end{tabular}

*'Asylum-seeker' is legally different from 'refugee'. For ease of readability, we group refugee and asylum-seeker together using the term 'refugee' in most of our writings, unless it is necessary to differentiate them. and subject headings, including relevant terms related to "migrant*", "refugee*", "social capital", "health*", "disease prevention", "disease management" and "qualitative/interpretive research". Broad concepts of "health", "prevention" and "disease management" were used instead of NCDs to capture more potential results. We used Boolean operators, wildcards and truncation appropriately. Additionally, we screened reference lists of all included articles for further inclusion.

\section{Identifying relevant articles}

We imported database search results into EndNote and removed duplicates. The first and second authors independently screened titles and abstracts against eligibility criteria (table 2), with all discordant articles included in full text screening. The authors then independently screened remaining full texts against eligibility criteria, with discrepancies discussed with the last author until consensus was reached. Acknowledging that the term 'migrant' is not universally defined, we included all articles on low-income immigrants unless authors explicitly indicated participants' citizenship status in host countries, thus those who were undocumented, possessed precarious legal status, hired as unskilled workers, worked in informal sectors or lived in a deprived neighbourhood were included. There have been debates on the framing of NCDs, ${ }^{48}$ including the pros and cons of integrating mental health and NCD management. ${ }^{49}$ In this synthesis, we restricted our focus to the four main NCD types (ie, cancers, cardiovascular diseases, chronic respiratory diseases, diabetes) to enable a deeper and more focused analysis. We included all aspects of preventing and managing these NCDs, such as health literacy, healthcare access, prevention, management and outcomes. During literature identification, we found substantial bodies of work related to social capital and mental health or HIV, indicating the need for similar specific syntheses in these areas of work. Figure 1 documents study selection using the Preferred Reporting Items for Systematic Reviews and Meta-Analyses. ${ }^{51}$

\section{Extraction and quality appraisal}

We extracted data to a spreadsheet using the following headings: lead author, publication year, study objectives, study country, study period, sampling, data collection, analysis, participants (ie, numbers, country of origin, immigration status, age range, gender), NCD focus and social capital findings. We assessed methodological strengths and limitations of included studies using the Critical Appraisal Skills Programme Checklist for Qualitative Research. ${ }^{52}$ Adopting Malpass et al s method we categorised studies as: (1) key article, conceptually rich and could potentially make a significant contribution to the synthesis; (2) satisfactory article, which could potentially contribute to the synthesis and (3) unsure, as the article was either less relevant or we had doubts about its methodological rigour. ${ }^{53}$ Overall, most articles were satisfactory and contributed substantially to our synthesis, 


\begin{tabular}{|c|c|c|}
\hline Criteria & Inclusion & Exclusion \\
\hline $\begin{array}{l}\text { Exposure of } \\
\text { interest }\end{array}$ & $\begin{array}{l}\text { Any component of social capital (including bonding, bridging, linking, friends, family, } \\
\text { relatives, neighbours, kinship, provider patient relationship, social isolation, social } \\
\text { network, social cohesion, social participation, social support, social connection, social } \\
\text { mobilisation, community capital, community network, community cohesion, community } \\
\text { participation, community support, community connection, community mobilisation, trust, } \\
\text { mistrust, reciprocity, emotional support, psychosocial support, neighbourhood cohesion, } \\
\text { collective efficacy, solidarity, empowerment, civil society) }\end{array}$ & $\begin{array}{l}\text { Studies that explored only social } \\
\text { capital without linking them to any } \\
\text { aspect of NCDs. }\end{array}$ \\
\hline $\begin{array}{l}\text { Outcomes of } \\
\text { interest }\end{array}$ & $\begin{array}{l}\text { NCD prevention (including lifestyle behaviours), NCD management, access to healthcare } \\
\text { facilities for NCD care, NCD outcomes including one of cancers, cardiovascular } \\
\text { diseases, chronic respiratory diseases, and diabetes }\end{array}$ & $\begin{array}{l}\text { Studies that explored NCD } \\
\text { perception and experiences without } \\
\text { linking them to social capital. }\end{array}$ \\
\hline $\begin{array}{l}\text { Population } \\
\text { groups }\end{array}$ & $\begin{array}{l}\text { Refugees, asylum-seekers, low-wage migrant workers, low-skilled migrants, } \\
\text { undocumented migrants, immigrants who lived in poverty, migrants with precarious } \\
\text { status, forced migrants (including trafficking victims) }\end{array}$ & $\begin{array}{l}\text { Studies that looked at expatriates, } \\
\text { white-collar migrants, and internal } \\
\text { migrants (rural-urban/urban-rural). }\end{array}$ \\
\hline $\begin{array}{l}\text { Research } \\
\text { method used }\end{array}$ & Any qualitative methods, or mixed methods if they reported qualitative findings & Quantitative methods and findings \\
\hline $\begin{array}{l}\text { Publication } \\
\text { type }\end{array}$ & Primary studies published in academic journals* & $\begin{array}{l}\text { Reviews, opinion piece, conference } \\
\text { proceedings, editorials and protocols }\end{array}$ \\
\hline $\begin{array}{l}\text { Publication } \\
\text { year }\end{array}$ & Published in or after $1990 \dagger$ & \\
\hline Language & Any that includes an English abstract & No English abstract \\
\hline
\end{tabular}

*Only academic journals were included to apply a standardised appraisal in the quality assessment on qualitative research to all studies. †These dates were chosen as most public health studies related to social capital were published after 1990.

NCDs, non-communicable diseases.

including three key articles. We categorised ten articles as 'Unsure' and reassessed how each of these articles influenced the overall synthesis towards the end. We found that 'key' and 'satisfactory' articles shaped overall synthesis with support from 'unsure' articles. We noted that a minor synthetic element on negative perspective of social contagion came solely from articles in the 'unsure' category. Table 3 presents the summary and assessment of included articles.

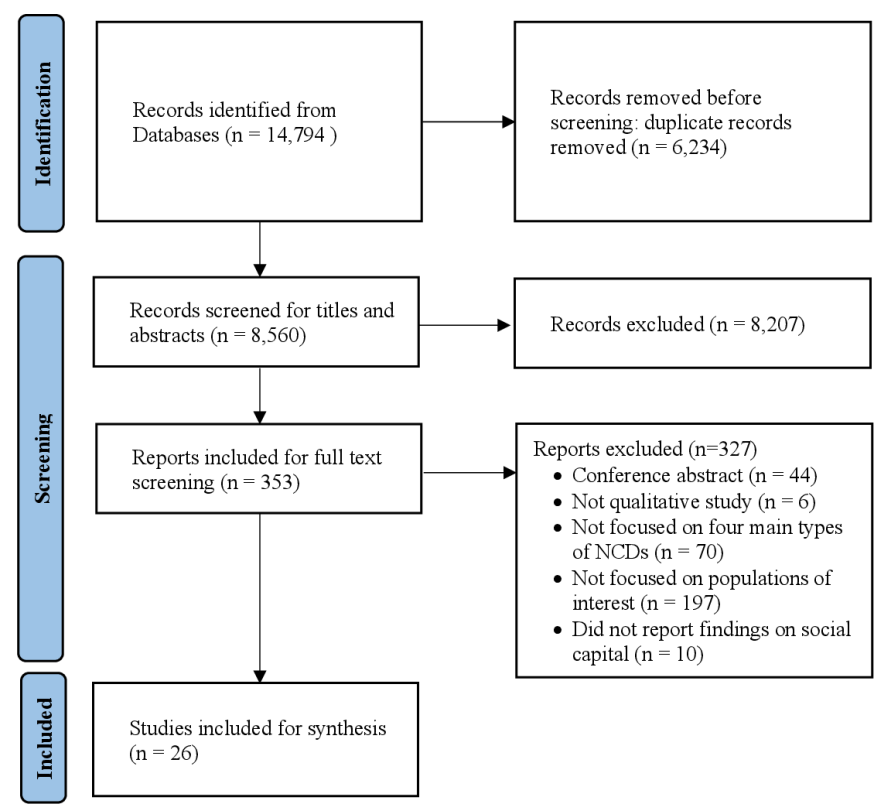

Figure 1 PRISMA diagram. NCDs, non-communicable diseases; PRISMA, Preferred Reporting Items for Systematic Reviews and Meta-Analyses.

\section{Synthesising data}

We synthesised included studies in Nvivo V.12, using the meta-ethnography approach developed by Noblit and Hare that emphasises comparative understanding rather than data aggregation. ${ }^{41}$ This approach involved translation and synthesis of translation through analysing metaphors (eg, concepts and themes). First, the first and second authors conducted initial blinded double-coding of ten articles. In studies with mixed participants (eg, migrants, refugees, healthcare providers, community health workers), we coded only results relevant to migrants and refugees. We compared initial codes, noted inductive themes and established a preliminary thematic structure. We read and reread all studies, using an interpretivist lens in an iterative process of interpreting and discussing each coauthor's understanding of key concepts and their meanings. We held regular meetings to discuss preconceived ideas and potential biases to check reflexivity. We constantly referenced theoretical concepts on social capital and migration to enable deeper understanding of article authors' interpretations. We juxtaposed articles to establish how they related to each other and noted that all concepts were either reciprocal or formed lines of arguments, and none was refutational.

\section{Patient and public involvement}

Patients and the public were not involved in any stage of this study.

\section{RESULTS}

Table 3 shows 26 included articles of 14784 initially identified. In total, 20 studies were conducted in the USA, 4 in 

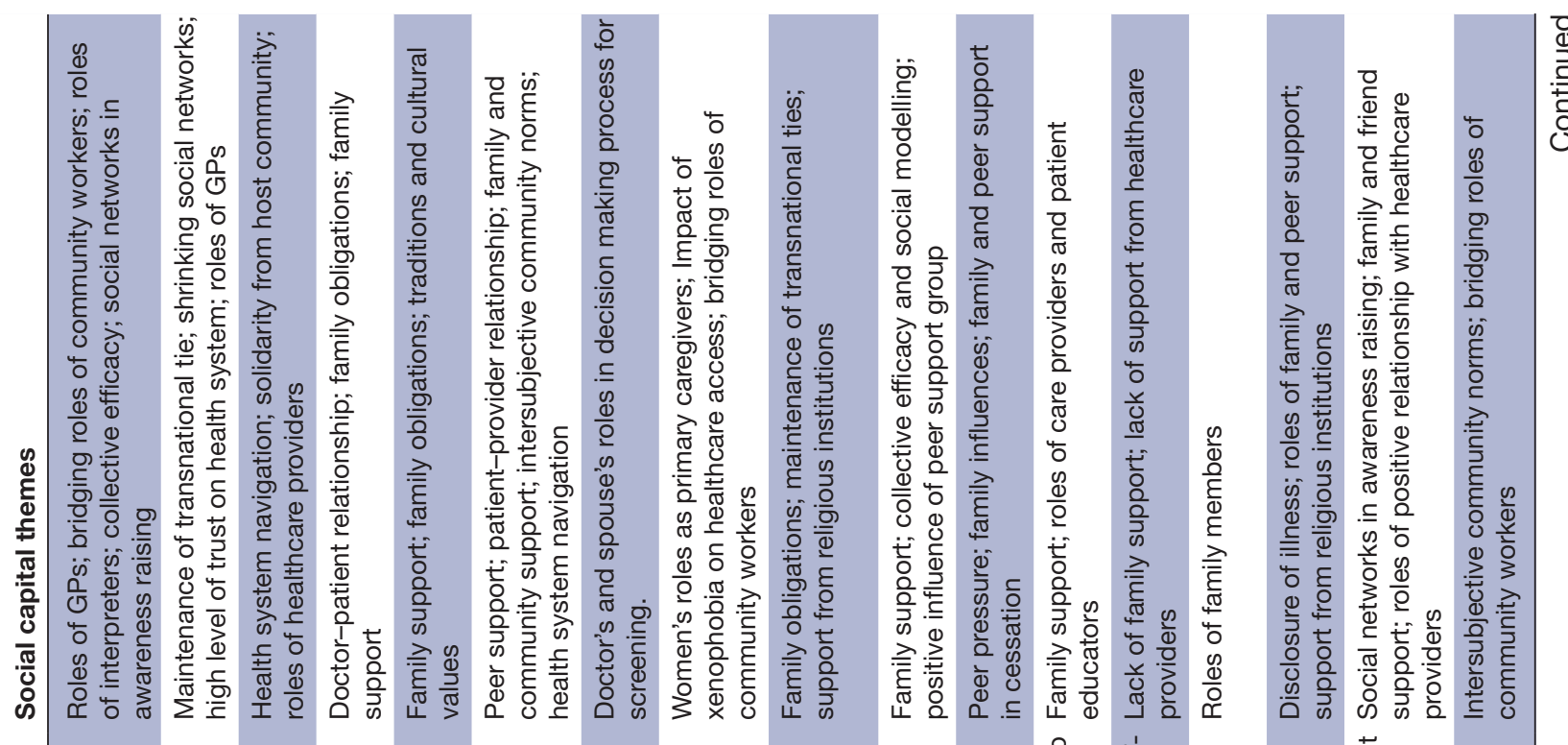

बळ

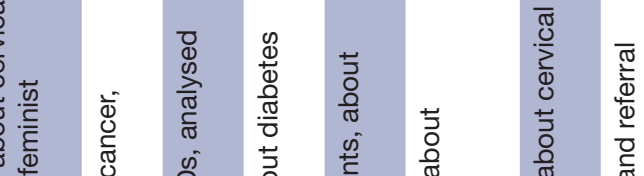
is

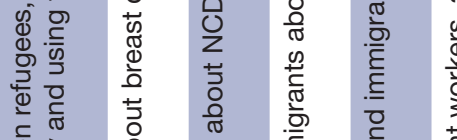

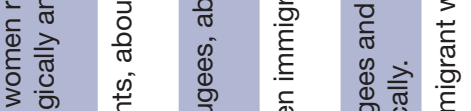

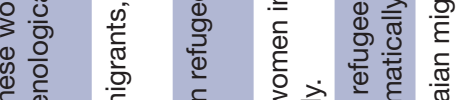

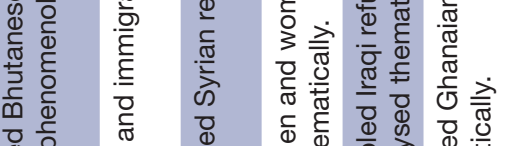

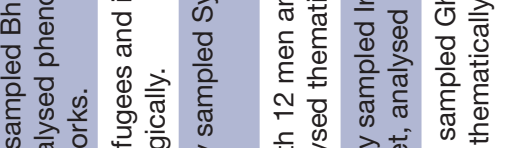
त्रे

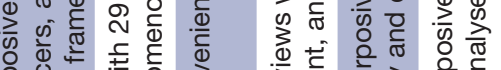

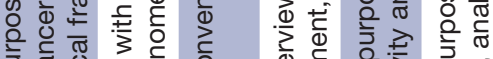

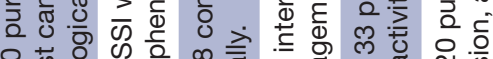

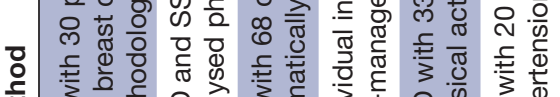

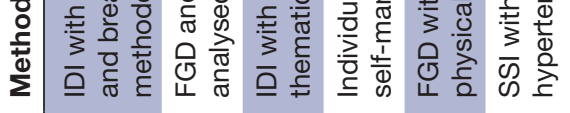

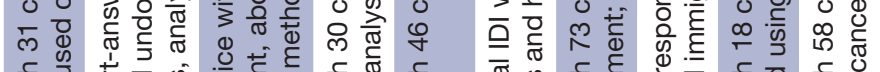

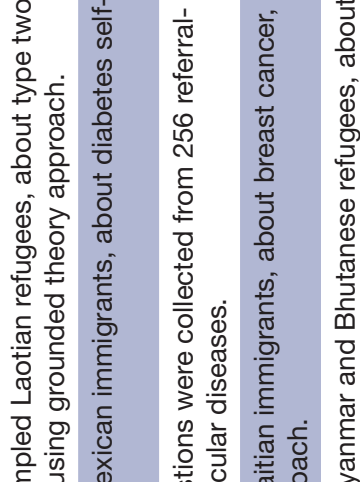

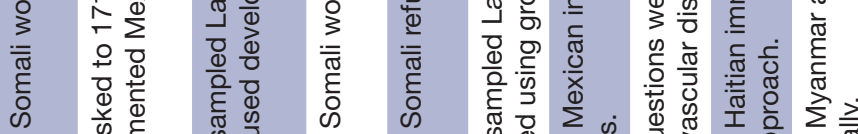

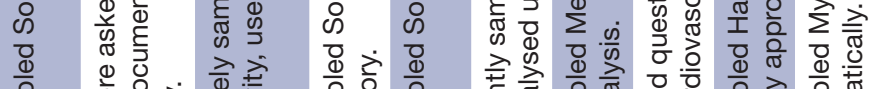

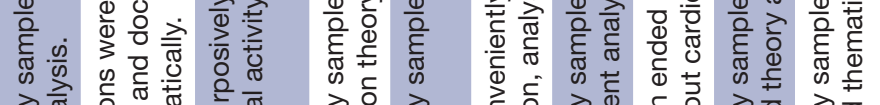

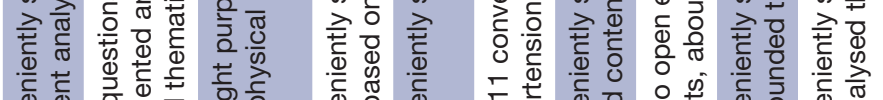
: ర人

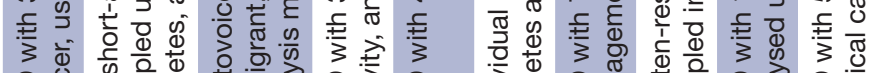

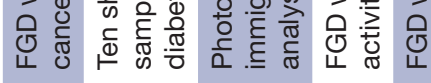
紊要

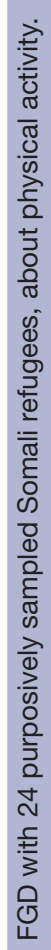




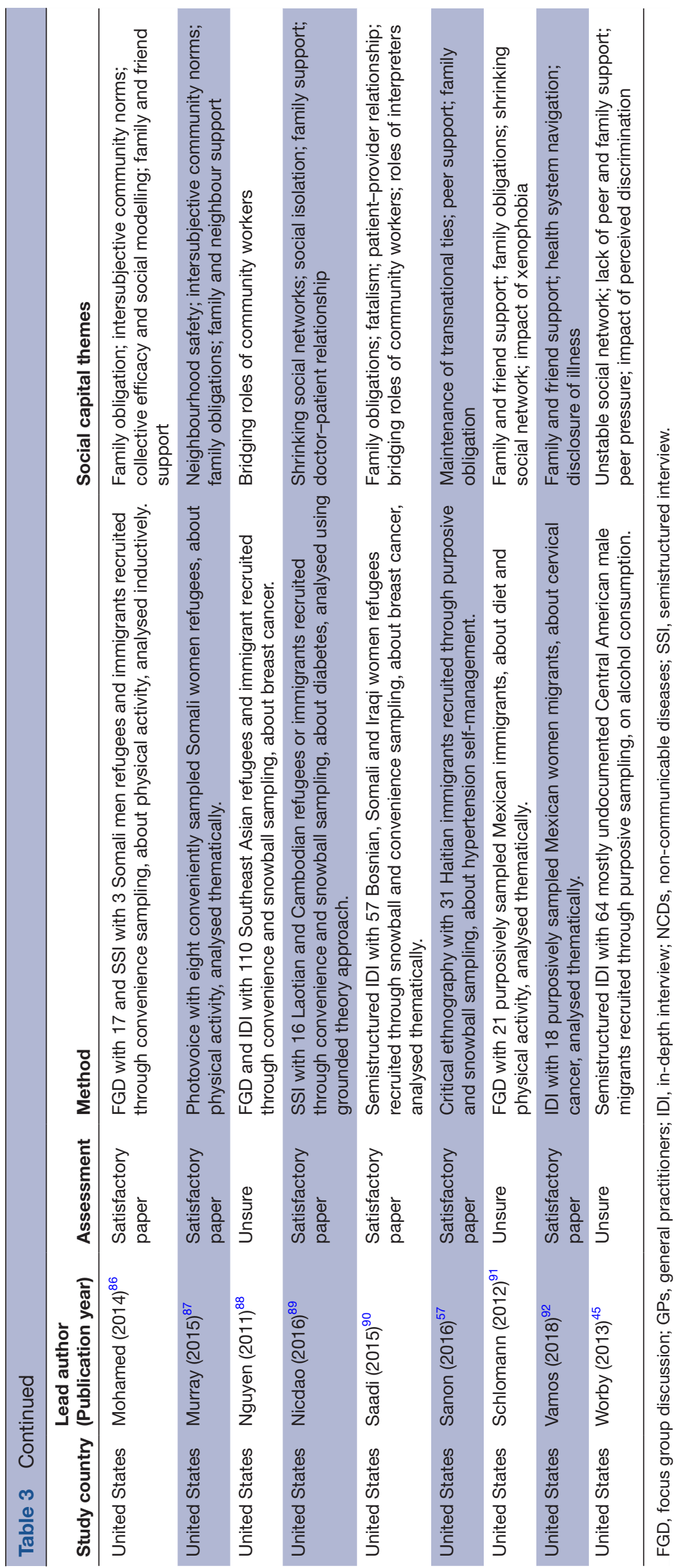


Europe (ie, Denmark, Netherlands, Sweden) and 1 each in Australia and Jordan. All were published after 2000, with 15 including refugees while the rest focused on lowincome immigrants, migrant workers or undocumented migrants. Ten studies focused on NCD prevention (eg, physical activity, diet, smoking and drinking) and access to NCD services, eight focused on cancer prevention and management (breast and cervical), and eight discussed diabetes and hypertension management. None of the eligible studies examined social capital using established theories or constructs, indicating the existing literature is generally undertheorised. This required a more interpretative approach to review findings than might normally be the case. We thus interpreted data from included studies based on established social capital theories, presenting our findings under two sections: (1) accessing appropriate healthcare services and (2) social capital in accessing NCD prevention and management. The first section contextualises the complex situation migrants and refugees experienced in host countries, while the second synthesises the social capital available and used to overcome difficulties.

\section{Accessing appropriate healthcare services}

The most salient themes within healthcare access were affordability and functional health literacy. Access to healthcare was largely compounded by financial hardship and difficulties in navigating the health system. Poverty caused their prioritisation of basic survival needs over health.

Here it is like a luxury to get sick. You have to go work even if you are sick. And a doctor is so expensive that it's a luxury to even go to the doctor. (Mexican migrant in the US, Article \#24)

While insurance was available to relieve financial stress for medical care among migrants and refugees in some countries, ease of access was often compromised by a complex and bureaucratic system untailored to their needs. ${ }^{54-57}$ Copayment and opportunistic costs further hindered their receipt of necessary health services. Although most described host country health systems as more advanced, navigating these systems was challenging and often confusing, and exacerbated by low health literacy, lack of legal status and language barriers. ${ }^{4755859}$ Consequently, some chose to get medicines from pharmacies and seek care from emergency services or private practices; ultimately incurred even higher costs. These experiences were intensified if the host country had an exclusionary healthcare system that penalised migrants and refugees.

\section{Social capital in accessing ncd prevention and management}

Structural, economic and sociocultural forces were integral in influencing migrants' and refugees' NCD prevention and management. Social capital in the forms of emotional, informational, logistic and linguistic supports thus became essential in subverting structural deterrents to seeking healthcare services. Interactions between social and individual roles were mediated by social capital, described under eight themes related to postmigration adjustment, family, transnational ties, friends, community, bridging capital and linking capital. Figure 2 presents the thematic scheme.

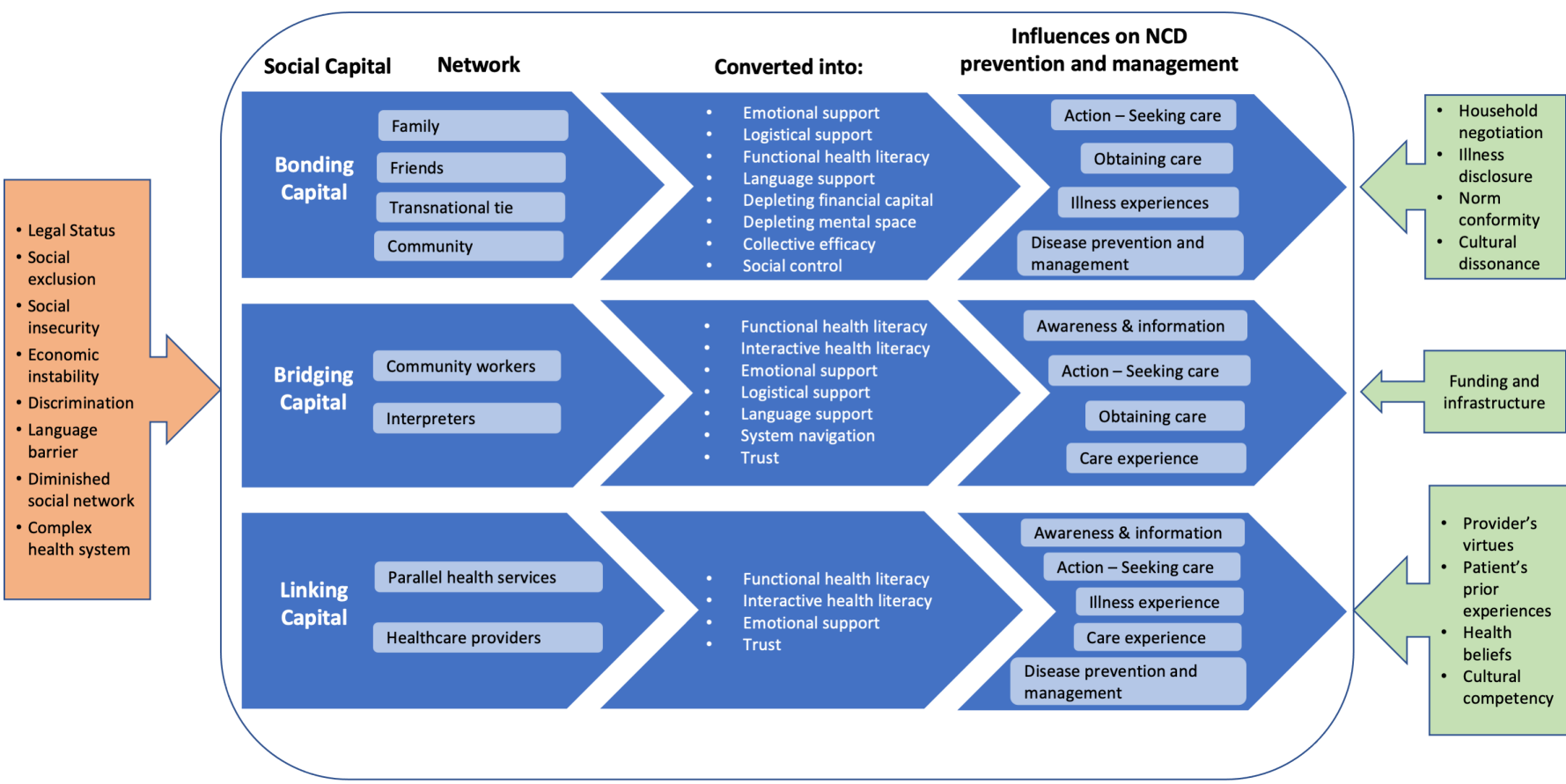

Figure 2 Contextual factors, conversion of social capital and its' interacting factors. NCDs, non-communicable diseases. 
Postmigration: adjustment to a new system with diminished social networks

Migrants and refugees had difficulty adapting to host countries. Their full participation in society was obstructed by legal status, stigmatisation and language barriers. This lack of civic engagement further marginalised them, limiting health choices.

My elderly mother used to walk to the mosque in the early morning... a car chased her and her friend as they walked... It was a man in a pick-up truck who was insulting them as they walked home. They refused to walk there again after that incident. (Somali refugee in the US, article \#15)

The complex and prolonged process of adjustments to survive in host countries caused overwhelming stress, and was perceived as a root cause of physical and mental illnesses.

[I] t's a stressful, stressful life and you forget about many things. You forget to live you're working so hard. You forget about social life, forget about yourself. (Mexican immigrant in the US, Article \#24)

Social insecurity and economic instability further hindered NCD prevention and management. Livelihood stressors, combined with shrinking social networks postmigration, positioned work and health as competing priorities. Working multiple jobs or long hours was common for household survival, subsequently undermining NCD prevention and care.

We all know that exercise leads to good health. Then again, people cannot keep it up. We won't have time, looking for food, jobs and paychecks. (Somali refugee in the US, article \#15)

\section{Family: core of social capital and double-edged sword}

Family members appeared to be the primary source of social capital in NCD prevention and treatment. Those living alone in host countries lacked the protection extended by families. They often felt isolated and did not receive adequate support for disease management. Those living with families in host countries, received emotional support and bridging to healthcare systems. For example, educated family members read and translated health information, provided transportation, assisted with system navigation, and communicated with health workers for those not fluent in host country languages.

Changes in household compositions and community dynamics postmigration required shifting strategies. When community networks for health were limited, NCD management depended on negotiations within households. These included tasks distribution to maximise financial and human capital with factors such as family tradition, cultural values, meal habits and gender roles highlighted in negotiations. Some families were receptive to required dietary changes. For others, family traditions, cultural values, and habits contravened lifestyle recommendations and reduced adherence.

[W] hen I meet relatives, they invite me [to eat] all the time, and I cannot say no...; this is considered impolite not to eat the food when offered; It is hard to say no to good food that you get served; My family thinks I'm too small, but I'm overweight! They offer me different dishes and meals the whole time. (Arab migrant in Sweden, Article \#20)

Differences were also observed between genders. Men tended to obtain more spousal support for healthy eating, while women's dietary behaviours were reliant on family's acceptance.

A challenge for me has been to convince my husband to use less oil and convince my children to eat less fried foods and sweets. (Latino migrant in the US, Article \#10)

Migrant women who worked were exhausted by household chores and described physical exhaustion as compromising their abilities to adopt preventive health practices.

\section{Transnational ties: costs of tie maintenance}

How kinship was managed postmigration affected NCD prevention and management. Financial remittances were usually necessary in exchange for social capital extended by families in countries of origin. The emotional comfort received from their family affirmed their identities as responsible children, spouses and parents. To fulfil familial responsibilities, migrants focused on converting limited available resources (ie, time, mental space, physical capacities) into financial capital, deprioritising NCD preventive practices.

Taking care of the children in Haiti, I think it does not make hypertension well. Because most of the times, you do not have the economy even for your own self if you were to get sick while you do not have insurance. (Haitian migrant in the US, Article \#23)

For migrants with NCDs, the struggle to provide for their families became a motivation to manage their diseases as health was prerequisite to maximising income through labour.

If I were to tell you the amount of money I send to Haiti, I could not talk about that, girl. I can tell you everything I make where it goes is Haiti because all my soul is in Haiti. [I have] six children in Haiti. If I were to let hypertension kill me, who would take care of them? So I am obligated to take my medications. (Haitian migrant in the US, Article \#23)

Similarly, refugees who were uprooted from their home countries were apprehensive about relatives' health and safety across borders. These worries overwhelmed their daily life and intensified their need to maintain transnational ties for emotional comfort and bonding. Consequentially, NCD preventive practices and management were minimised.

For diabetes patients, diet and food is not important. The mood and mentality play [a] big role. For instance, [if] I receive a call from Damascus, I feel sad for one month. I 
am the only one who left the prison. [...] Diabetes cannot be stable as long as my family is living like that. (Syrian refugee in Jordan, Article \#14).

Friends: sources of informational, emotional and logistical support Together with family, close friends within the same social group were significant in extending emotional, informational and sometimes logistical support to migrants and refugees. Friend ties were especially crucial for those separated from family. However, migrants and refugees were cautious about friends' support in illness management. Disclosure of illness, especially those perceived as stigmatised (eg, cervical cancer), could negatively affect friendships.

Illness should be confidential; you are not supposed to talk about your illness to just anybody. Once you talk about your illness, you get a bad feeling because the person you are telling pulls away from you. (Haitian migrant in the US, article \#11)

On acceptance of disclosure, participants often benefitted from friends' emotional and practical support. However, disclosure was still perceived as risk-taking.

\section{Communities: distributed health literacy versus perceived social control}

Community networks, including religious, cultural and grassroots support groups, provided a sense of security and enabled reciprocal exchanges of information and other practical support that enhanced NCD management. Community attachment fostered social cohesion and facilitated diffusion of health information. Network participants shared various health literacy skills to enable health promotion, while providing a platform for collective efficacy and role modelling.

The second camel follows the steps of the first camel, you are what your friend is, and if you want to know somebody, look at his friends. (Somali refugees in the U.S., Article \#06)

However, potential harms of communal bonds were noted such as facilitating risk behaviours.

What? Are you too proud to drink with us? [...] It is hard to avoid them, I must pass through the living room to go to my room, and they are there, playing music and drinking

(Guatemalan migrant in the US, article \#26)

Transnationalism played an instrumental role in the search for recognition of a shared identity, defined as a set of culturally mandated norms and expectations of group members. The perceived need to observe intersubjective community norms in the host countries exerted ongoing social control.

There is no place just for women, and that is the only barrier I can see. (Somali refugee in the US, article \#5)

Cultural dissonance was apparent in some communities in which, for example, joining western facilities such as gyms and following modern norms such as wearing sports attire were regarded as inappropriate.

If you give an old (Somali man) a pair of shorts and Somali women see him running, Somali women will say he is crazy. (Somali refugee in the US, article \#16)

Observing community norms in host countries often conflicted with effective NCD preventive practices and management, inhibiting lifestyle modification. Some health behaviours such as losing weight through exercising were seen as 'an act of vanity ${ }^{44}$ or betrayal of cherished beliefs.

Bridging capital: getting ahead with brokers of healthcare access The structural, financial and language barriers to healthcare access could be narrowed by 'bridges' within communities. Difficulties in healthcare navigation were alleviated through community health workers, peer advocates or settlement workers. These agents provided emotional, informational, linguistic and logistical support bridging communities with healthcare systems. They were often well equipped with necessary skills and information to assist migrants and refugees beyond what closer networks could provide. These broker networks increased health literacy and facilitated adaptation in host countries.

If we didn't have someone who spoke our language, I can't imagine how difficult life would have been. (Somali refugee in the US, article \#22)

\section{Linking capital: parallel health services in contexts of social exclusion}

Humanitarian organisations were important resources in linking migrants and refugees to adequate NCD care. They filled the access gap by providing primary healthcare and referral services, delivering services tailored to participants' needs which effectively reduced physical barriers and opportunistic costs of visiting a clinic.

At first, they gave us instructions for using the device [blood pressure monitor]. [...] They come here every time. Things are good. (Syrian refugee in Jordan, Article \#14)

These parallel services were especially crucial in countries with exclusionary national health policy against noncitizens. However, such services were often limited due to lack of funding and infrastructure.

Linking capital: patient-centred care for underserved populations Relationships with healthcare providers determined the quality of care received and ultimately NCD prevention and management. Healthcare providers, especially physicians, were sources of health information. This was especially essential as mainstream health information often lacked cultural competency for migrants' and refugees' specific health and language needs. Trust and respect for physicians became the guide and initiator for NCD management, such as screening, lifestyle modification and treatment adherence. 
Whenever my doctor schedules an appointment for me, I am always obligated to go and there is never any problem or difficulties with that. I respect doctors and their opinion. First there is a God, and then there is a doctor. (Bosnian refugee in the US, Article \#22)

General practitioners often served as gateways to comprehensive care. Given migrants' and refugees' social position, more efforts were required to access this first point of contact, and failure hindered their access to adequate health services.

However, relationships with healthcare providers were highly contextual and inconsistent across studies, and shaped by provider virtues. High trust was placed on providers who exhibited professional conduct such as empathy, compassion and confidentiality. Other providers' nonchalant approach left migrants and refugees feeling unsupported. Those who experienced traumatising encounters in their countries of origin experienced intensified fear and mistrust in establishments, including healthcare providers. Scepticism about prescriptions and physician recommendations was common among those who believed in divine will, which affected their healthcare usage.

\section{Some people do everything right, they eat right, they exer- cise, and cancer still comes on them, so you cannot tell me you have control. Even when you take care of the first can- cer, it can go back. So, the control is God. (Haitian migrant in the US, Article \#11)}

Discordance between migrants' and refugees' needs and provider expectations also caused distress in NCD management. For example, lifestyle prescriptions that lacked cultural sensitivity and considerations of individual circumstances often failed to ensure patient engagement.

Language differences in healthcare settings needed to be managed adequately to avoid eroding trust. Interpretation services could empower participants to exercise patient rights and improve health literacy, but experiences with interpreters were not always positive. This sometimes led to more frustration when expectations were mismatched.

When we go to the hospital, we are not able to tell our problems openly or clearly. They will give us an interpreter by phone because we are not in a condition to speak. But the interpreter tells us to speak louder... Sometimes the interpreter themselves won't understand what we are saying because we are not in the condition to speak due to pain and keeps asking. (Bhutanese refugee in the US, article \#12)

Although interpretation services were negatively perceived in some settings, they often enabled more effective communication among migrants and refugees with healthcare providers. Conversing in native languages through interpreters empowered them to discuss NCD treatment plans with providers, which ultimately improved treatment outcomes.
If GPs give the information, it would be good. They will listen, but if there is no interpreter, they cannot get a complete picture of any health problem and motivate them [women] to do these screening tests. (Bhutanese refugee in Australia, article \#21).

\section{DISCUSSION}

To the best of our knowledge, the study is the first attempt to synthesise qualitative evidence on the roles of social capital in NCD prevention and management among migrants and refugees using a meta-ethnography approach. Our findings highlighted the types of social capital, although limited, which migrants and refugees converted into necessary resources for NCD care. Against the backdrop of low financial and human capital, migrants and refugees needed to adapt to diminished social networks, manage transnational ties and navigate complex systems in host countries. These factors influenced their illness experiences and abilities to manage chronic diseases. Notably, barriers to adequate health services for the populations were relatively uniform across studies and were reduced through kinship and network ties. Community health workers, peer advocates or settlement workers, and other institutionalised assistance provided informational and practical supports, and brokered access to health services. These community resources were essential in improving functional, interactive and critical health literacy, consequently empowering their clients to act. Granovetter noted in 'the strength of weak ties' that linking groups across greater social distance is especially significant in information diffusion. ${ }^{31}$ Most linking networks among migrant and refugee communities were not bottom-up initiatives due to contextual limitations. Assistance was mostly through institutionalised delivery by governments or humanitarian organisations, suggesting the significant role of structural forces and institutional actors in building social capital in these populations.

In communities experiencing social exclusion, the conversion of social capital into practical resources was integral in improving health literacy, increasing access to appropriate healthcare and adhering to prescribed treatment and self-management of chronic illness. ${ }^{6061}$ However, such conversion among migrants and refugees sometimes brought undesirable outcomes, especially when health recommendations were not congruent with perceived cultural norms and family dynamics. Thus, it is important to understand how they may externalise illness experiences within social environments that are culturally circumscribed and may inhibit changes in lifestyle. ${ }^{62}$ This finding highlighted how culture intertwines with socioeconomic situations and eventually shapes unique health needs. $^{63}$

The relationships between healthcare providers and migrants were diverse, sometimes contradictory and contextual, often shaped by prior experiences, belief systems and quality of available services. Inequality, social 
relations, and structural forces impact communication between providers and patients; and quality of communication could be improved through an 'exchange' instead of a 'transfer' of information. ${ }^{64}$ Migrants' and refugees' relationship with providers influenced quality of care and ultimately health outcomes. ${ }^{65}$ Some established strategies to address the issue include improving providers' cultural competency, ${ }^{63}$ encourage reciprocal and dynamic communication, and addressing health beliefs. ${ }^{65}$

\section{Implications for policy and research}

Our review revealed a dearth of qualitative studies about social capital and NCDs among migrant and refugee populations. Importantly, none of these studies explored social capital based on established theories, instead using terms such as trust, support and networks. This scarcity is especially palpable in non-western regions, despite the high numbers of migrants and refugees hosted in these countries and an increasing trend of NCDs observed. ${ }^{1866-69}$ Despite having some of the most congested migration routes and supplying the highest number of international migrants globally, none of our included studies were from Asia. Consequently, perspectives from Asia, West Asia ('Middle East') and Africa are substantially lacking. Our findings corroborate a bibliometric analysis showing global migrant health research was dominated by highincome destination countries and focused on psychosocial, mental health, and health policy and systems with only $8.9 \%$ focused on NCDs. ${ }^{70}$ This reflects national and global public health research priorities, and the inequalities in scientific research across scopes, populations of interest and countries, substantiating the need for global health decolonisation. ${ }^{71}$

The data of social capital and NCD were insufficient to build a holistic understanding of how different dimensions of social capital influenced the continuum of NCD outcomes. While more studies globally have linked social capital to NCDs in recent years, ${ }^{38} 607273$ very few qualitative studies were grounded in established social capital theories. The scarcity of such literature is more evident for migrants and refugees. Future research needs to explore how social capital is converted into resources required to prevent and manage NCDs based on established theories and concepts.

Our synthesis also highlighted the lack of cultural competency and effective provider-patient relationship with migrants and refugees, implying health systems are unequipped to address their needs. With increasing population mobility, the relevance of national health systems for non-citizens needs greater discussion. Their needs should be considered for achieving universal health coverage. Global health governance should emphasise rights-based universal health equity among migrants and refugees. ${ }^{74}$

\section{Limitations}

Electronic databases index qualitative studies differently, some with more limited terms than others. ${ }^{75}$ Some relevant qualitative studies might have been omitted despite searching most major databases. However, we kept search terms intentionally broad and screened the reference lists of included studies to ensure comprehensiveness. Further, though we included sources in any language, we used English search strings, so it is possible that relevant articles in languages other than English may have been omitted as we did not translate search strings. Study settings were concentrated in western contexts, with a lack of data and perspectives from Asia and Africa that reduced the generalisation of our synthesis. Lastly, key terms including 'migrant', 'immigrant', 'refugee' and 'asylum-seeker' are often loosely defined or misused in the literature and interpretations subject to historical and political revision. Further research and consensus are needed to establish terms that better define these mobile population groups to enable further in-depth analysis.

\section{CONCLUSIONS}

Migrants and refugees faced structural, economic, social and cultural barriers in healthcare access, jeopardising their ability to prevent and manage NCDs. Social capital, especially from family and institutional networks, facilitated NCD care. However, social capital alone was insufficient to address unmet health needs of migrants and refugees. Alongside community empowerment, addressing NCD needs for migrants and refugees requires inclusive public policies grounded in principles of equity and justice.

Acknowledgements We thank Mr. Miguel Kai-Chen Tan for his supporting in organising search results and extracting part of the data. The first author would like to acknowledge her child, Lia Yihan Mueller, who inspires her to see the world differently.

Contributors STT and HY conceived the study and developed the systematic review methodology. STT and PTAL ran the search strategy, screened references retrieved, selected eligible studies based on the eligibility criteria and critically appraised studies. STT performed primary coding. HY refined coding and finalised coding with STT. STT and HY conducted meta-ethnography analysis. STT wrote a draft of the manuscript with inputs from HY. HY and NH reviewed and edited the manuscript. HY is the guarantor for the work. All authors reviewed the final manuscript.

Funding This work was supported in part by the NUS Start-Up Grant, NUS Efforts Against COVID-19 (NUSEAC), and WHO APO (Asian Pacific Observatory on Health Systems and Policies) Grant.

Competing interests None declared.

Patient consent for publication Not applicable.

Provenance and peer review Not commissioned; externally peer reviewed.

Data availability statement Data are available on reasonable request.

Supplemental material This content has been supplied by the author(s). It has not been vetted by BMJ Publishing Group Limited (BMJ) and may not have been peer-reviewed. Any opinions or recommendations discussed are solely those of the author(s) and are not endorsed by BMJ. BMJ disclaims all liability and responsibility arising from any reliance placed on the content. Where the content includes any translated material, BMJ does not warrant the accuracy and reliability of the translations (including but not limited to local regulations, clinical guidelines, terminology, drug names and drug dosages), and is not responsible for any error and/or omissions arising from translation and adaptation or otherwise.

Open access This is an open access article distributed in accordance with the Creative Commons Attribution Non Commercial (CC BY-NC 4.0) license, which permits others to distribute, remix, adapt, build upon this work non-commercially, 
and license their derivative works on different terms, provided the original work is properly cited, appropriate credit is given, any changes made indicated, and the use is non-commercial. See: http://creativecommons.org/licenses/by-nc/4.0/.

\section{ORCID iDs}

Sok Teng Tan http://orcid.org/0000-0003-2139-9922

Natasha Howard http://orcid.org/0000-0003-4174-7349

Huso Yi http://orcid.org/0000-0003-4724-5235

\section{REFERENCES}

1 Berry A. Anti-immigrant attitudes rise worldwide: Poll. DW, 2020. Available: https://www.dw.com/en/anti-immigrant-attitudes-riseworldwide-poll/a-55024481 [Accessed 7 Apr 2021]

2 Pavli A, Maltezou $\mathrm{H}$. Health problems of newly arrived migrants and refugees in Europe. $J$ Travel Med 2017;24:1-8.

3 Penchansky R, Thomas JW. The concept of access: definition and relationship to consumer satisfaction. Med Care 1981;19:127-40.

4 Levesque J-F, Harris MF, Russell G. Patient-Centred access to health care: conceptualising access at the interface of health systems and populations. Int J Equity Health 2013;12:18.

5 Chuah FLH, Tan ST, Yeo J, et al. The health needs and access barriers among refugees and asylum-seekers in Malaysia: a qualitative study. Int J Equity Health 2018;17:1-15.

6 Loganathan T, Rui D, Ng C-W, et al. Breaking down the barriers: understanding migrant workers' access to healthcare in Malaysia. PLoS One 2019;14:e0218669-24.

7 Biswas D, Kristiansen M, Krasnik A, et al. Access to healthcare and alternative health-seeking strategies among undocumented migrants in Denmark. BMC Public Health 2011;11:11.

8 Mangrio E, Sjögren Forss K. Refugees' experiences of healthcare in the host country: a scoping review. BMC Health Serv Res 2017; $17: 814$

9 Nutbeam D, Lloyd JE. Understanding and responding to health literacy as a social determinant of health. Annu Rev Public Health 2021;42:159-73.

10 Legido-Quigley $\mathrm{H}$, Pocock N, Tan ST, et al. Healthcare is not universal if undocumented migrants are excluded. $B M J$ 2019;366:14160.

11 Etienne CF. Achieving universal health coverage is a moral imperative. Lancet 2015;385:1271-3.

12 Landau LB, Dodson BM, Uhlmann J. Local inclusion of migrants and refugees: a gateway to existing ideas, resources and capacities for cities across the world, 2020. Available: http://www.oecd.org/ regional/Local-inclusion-Migrants-and-Refugees.pdf

13 Kavukcu N, Altıntaș KH. The challenges of the health care providers in refugee settings: a systematic review. Prehosp Disaster Med 2019;34:188-96.

14 Rechel B, Mladovsky P, Devillé W. Migration and health in the European Union. Berkshire: Open University Press, 2011.

15 World Health Organization (WHO). Noncommunicable diseases, 2021. Available: https://www.who.int/news-room/fact-sheets/detail/ noncommunicable-diseases [Accessed 6 Sep 2021].

16 Di Cesare M, Khang Y-H, Asaria P, et al. Inequalities in noncommunicable diseases and effective responses. Lancet 2013;381:585-97.

17 Agyemang C, van den Born B-J. Non-Communicable diseases in migrants: an expert review. J Travel Med 2019;26. doi:10.1093/jtm/ tay107. [Epub ahead of print: 01 Feb 2019].

18 Amara AH, Aljunid SM. Noncommunicable diseases among urban refugees and asylum-seekers in developing countries: a neglected health care need. Global Health 2014;10:24.

19 Yun K, Hebrank K, Graber LK, et al. High prevalence of chronic noncommunicable conditions among adult refugees: implications for practice and policy. J Community Health 2012;37:1110-8.

20 Doocy S, Lyles E, Hanquart B, et al. Prevalence, care-seeking, and health service utilization for non-communicable diseases among Syrian refugees and host communities in Lebanon. Confl Health 2016;10:21.

21 Doocy S, Lyles E, Roberton T, et al. Prevalence and care-seeking for chronic diseases among Syrian refugees in Jordan. BMC Public Health 2015;15:1097.

22 Doocy S, Sirois A, Tileva M, et al. Chronic disease and disability among Iraqi populations displaced in Jordan and Syria. Int J Health Plann Manage 2013;28:e1-12.

23 Hall E, Lee S-Y, Clark PC, et al. Social ecology of adherence to hypertension treatment in Latino migrant and seasonal Farmworkers. J Transcult Nurs 2016;27:33-41.
24 Wieland ML, Morrison TB, Cha SS, et al. Diabetes care among Somali immigrants and refugees. J Community Health 2012;37:680-4

25 Nugent R, Bertram MY, Jan S, et al. Investing in non-communicable disease prevention and management to advance the sustainable development goals. Lancet 2018;391:2029-35.

26 Marmot M. Social determinants of health inequalities. Lancet 2005;365:1099-104.

27 Dahlgren G, Whitehead M. European strategies for tackling social inequities in health: levelling up Part 2. Stud Soc Econ Determ Popul Heal 2006:1-105 http://www.euro.who.int/_data/assets/pdf_file/ 0018/103824/E89384.pdf

28 Putnam RD. Bowling alone: the collapse and revival of American community. Simon \& Schuster, 2000

29 Portes A. Social capital: its origins and applications in modern sociology. Annu Rev Sociol 1998;24:1-24.

30 Briggs deS X. Brown kids in white suburbs: housing mobility and the many faces of social capital. Hous Policy Debate 1998;9:177-221.

31 Granovetter MS. The strength of weak ties. In: Social networks. Elsevier, 1977: 347-67.

32 Villalonga-Olives E, Kawachi I. The dark side of social capital: a systematic review of the negative health effects of social capital. Soc Sci Med 2017;194:105-27.

33 WHO Regional Office for Europe. How health systems can address health inequities linked to migration and ethnicity. WHO Reg Off Eur, 2010.

34 Derose KP, Varda DM, Derose V. Social capital and health care access: a systematic review. Med Care Res Rev 2009;66:272-306.

35 Uphoff EP, Pickett KE, Cabieses B, et al. A systematic review of the relationships between social capital and socioeconomic inequalities in health: a contribution to understanding the psychosocial pathway of health inequalities. Int $J$ Equity Health 2013;12:54-12

36 Palafox B, Goryakin Y, Stuckler D, et al. Does greater individual social capital improve the management of hypertension? crossnational analysis of 61229 individuals in 21 countries. BMJ Glob Health 2017;2:e000443.

37 Flôr CR, Baldoni NR, Aquino JA, et al. What is the association between social capital and diabetes mellitus? A systematic review. Diabetes Metab Syndr 2018;12:601-5.

$38 \mathrm{Hu}$ F, Hu B, Chen R, et al. A systematic review of social capital and chronic non-communicable diseases. Biosci Trends 2014;8:290-6.

39 Gallant MP. The influence of social support on chronic illness selfmanagement: a review and directions for research. Health Educ Behav 2003;30:170-95.

40 Shiell A, Hawe P, Kavanagh S. Evidence suggests a need to rethink social capital and social capital interventions. Soc Sci Med 2020;257:111930.

41 Noblit GW, Hare RD. Meta-ethnography: synthesizing qualitative studies. Sage, 1988.

42 Sironi A, Bauloz C, Emmanuel M. Glossary on migration. Geneva: International Organization for Migration, 2019.

43 UNHCR. Convention and protocol relating to the status of refugees. Geneva: UNHCR, 2011.

44 Cartwright E, Schow D, Herrera S, et al. Using participatory research to build an effective type 2 diabetes intervention: the process of advocacy among female Hispanic farmworkers and their families in Southeast Idaho. Women Health 2006;43:89-109.

45 Worby PA, Organista KC. Contextual influences on the drinking of male Latino immigrant day laborers. Subst Use Misuse 2013;48:391-403.

46 UNHCR. Handbook on procedures and criteria for determining refugee status under the 1951 convention and the 1967 protocol relating to the status of refugees. Geneva, 1992.

47 McNatt ZZ, Freels PE, Chandler H. 'What's happening in Syria even affects the rocks': a qualitative study of the Syrian refugee experience accessing noncommunicable disease services in Jordan. Confl Heal 2019;13.

48 Adjaye-Gbewonyo K, Vaughan M. Reframing NCDS? an analysis of current debates. Glob Health Action 2019;12:1641043.

49 Stein DJ, Benjet C, Gureje O, et al. Integrating mental health with other non-communicable diseases. BMJ 2019;364:I295.

50 Ngo VK, Rubinstein A, Ganju V, et al. Grand challenges: integrating mental health care into the non-communicable disease agenda. PLoS Med 2013:10:e1001443.

51 Moher D, Liberati A, Tetzlaff J, et al. Preferred reporting items for systematic reviews and meta-analyses: the PRISMA statement. PLoS Med 2009;6:e1000097-6.

52 Critical Appraisal Skills Programme. CASP qualitative checklist, 2018. Available: https://casp-uk.net/casp-tools-checklists/ [Accessed 29 Nov 2019]. 
53 Malpass A, Shaw A, Sharp D, et al. "Medication career" or "moral career"? The two sides of managing antidepressants: a metaethnography of patients' experience of antidepressants. Soc Sci Med 2009;68:154-68.

54 Nyaaba GN, Agyemang C, Masana L, et al. Illness representations and coping practices for self-managing hypertension among sub-Saharan Africans: a comparative study among Ghanaian migrants and non-migrant Ghanaians. Patient Educ Couns 2019;102:1711-21.

55 Devlin JT, Dhalac D, Suldan AA, et al. Determinants of physical activity in somali women living in maine. Diabetes, 2010. Available: http://www.embase.com/search/results?subaction=viewrecord\& from=export\&id $=\mathrm{L} 71602170$

56 Kobetz E, Menard J, Dietz N, et al. Contextualizing the survivorship experiences of Haitian immigrant women with breast cancer: opportunities for health promotion. Oncol Nurs Forum 2011;38:555-60.

57 Sanon M-A, Spigner C, McCullagh MC. Transnationalism and hypertension self-management among Haitian immigrants. $J$ Transcult Nurs 2016;27:147-56.

$58 \mathrm{Hu}$ J, Amirehsani K, Wallace DC, et al. Perceptions of barriers in managing diabetes: perspectives of Hispanic immigrant patients and family members. Diabetes Educ 2013;39:494-503.

59 Lor B, Ornelas IJ, Magarati M, et al. We should know ourselves: Burmese and Bhutanese refugee women's perspectives on cervical cancer screening. J Health Care Poor Underserved 2018;29:881-97.

60 Kamimura A, Tabler J, Nourian MM, et al. Prevention and management of hypertension and diabetes using social capital and physical activity among socioeconomically disadvantaged populations. Fam Community Health 2017;40:205-11.

61 Vassilev I, Rogers A, Sanders C, et al. Social networks, social capital and chronic illness self-management: a realist review. Chronic IIIn 2011;7:60-86.

62 Lawton J, Ahmad N, Peel E, et al. Contextualising accounts of illness: notions of responsibility and blame in white and South Asian respondents' accounts of diabetes causation. Sociol Health IIIn 2007;29:891-906.

63 Kleinman A, Benson P. Anthropology in the clinic: the problem of cultural competency and how to fix it. PLoS Med 2006;3:e294.

64 Lee RG, Garvin T. Moving from information transfer to information exchange in health and health care. Soc Sci Med 2003;56:449-64.

$65 \mathrm{JF}$ H, Hons M, Anat DS. Doctor-Patient communication: a review. Spring 2010;10:38-43.

66 Tan S, Mitha K, Legido-Quigley H. 6.1-O5Effective ways to address the unmet ncd needs of Rohingya refugees in Malaysia. Eur J Public Health 2018;28.

67 Fiorini G, Cerri C, Bini S, et al. The burden of chronic noncommunicable diseases in undocumented migrants: a 1-yea survey of drugs dispensation by a non-governmental organization in Italy. Public Health 2016:141:26-31.

68 Finnerty F, George S, Eziefula AC. The health of recent migrants from resource-poor countries. Medicine 2018;46:66-71.

69 UNHCR. Trends at a glance: global trends forced displacement in 2019. UNHCR UN Refug Agency, 2020: 1-84.

70 Sweileh WM, Wickramage K, Pottie K, et al. Bibliometric analysis of global migration health research in peer-reviewed literature (2000-2016). BMC Public Health 2018;18:1-18.

71 Abimbola S, Pai M. Will global health survive its decolonisation? Lancet 2020;396:1627-8.

72 Kokab F, Greenfield S, Lindenmeyer A, et al. The experience and influence of social support and social dynamics on cardiovascular disease prevention in migrant Pakistani communities: a qualitative synthesis. Patient Educ Couns 2018;101:619-30.

73 Song Y, Nam S, Park S, et al. The impact of social support on self-care of patients with diabetes: what is the effect of diabetes type? systematic review and meta-analysis. Diabetes Educ 2017;43:396-412.
74 Smith R, Lee K. Global health governance: we need innovation not renovation. BMJ Glob Health 2017;2:e000275.

75 Dixon-Woods M, Bonas S, Booth A, et al. How can systematic reviews incorporate qualitative research? A critical perspective. Qual Res 2006:6:27-44.

76 Parajuli J, Horey D, Avgoulas MI. Best practice models recommended by Bhutanese refugee women for cervical and breast cancer screening in Australia: a qualitative study. Heal Promot J Aust 2019. doi:10.1002/hpja.315

77 Lue Kessing L, Norredam M, Kvernrod A-B, et al. Contextualising migrants' health behaviour - a qualitative study of transnational ties and their implications for participation in mammography screening. BMC Public Health 2013;13. doi:10.1186/1471-2458-13-431

78 Aweko J, De Man J, Absetz P, et al. Patient and provider dilemmas of type 2 diabetes self-management: a qualitative study in socioeconomically disadvantaged communities in Stockholm. Int $J$ Environ Res Public Health 2018;15. doi:10.3390/ijerph15091810. [Epub ahead of print: 2208 2018].

79 Olaya-Contreras P, Balcker-Lundgren K, Siddiqui F, et al. Perceptions, experiences and barriers to lifestyle modifications in first-generation middle Eastern immigrants to Sweden: a qualitative study. BMJ Open 2019;9:e028076. doi:10.1136/ bmjopen-2018-028076

80 Allen EM, Lee HY, Pratt R, et al. Facilitators and barriers of cervical cancer screening and human papilloma virus vaccination among Somali refugee women in the United States: a qualitative analysis. $J$ Transcult Nurs 2019;30:55-63. doi:10.1177/1043659618796909

81 D'Alonzo KT, Sharma M. The influence of marianismo beliefs on physical activity of mid-life immigrant Latinas: a Photovoice study. Qual Res Sport Exerc 2010;2:229-49. doi:10.1080/19398441.2010.4 88031

82 Giuliani KKW, Mire OA, Jama S, et al. Tobacco use and cessation among Somalis in Minnesota. Am J Prev Med 2008;35:S457-62.

83 Helsel D, Mochel M, Bauer R. Chronic illness and Hmong shamans. $J$ Transcult Nurs 2005;16:150-4.

84 Kim S, Koniak-Griffin D, Flaskerud JH, et al. The impact of lay health advisors on cardiovascular health promotion: using a communitybased participatory approach. J Cardiovasc Nurs 2004;19:192-9.

85 Marinescu LG, Sharify D, Krieger J, et al. Be active together: supporting physical activity in public housing communities through women-only programs. Prog Community Health Partnersh 2013:7:57-66.

86 Mohamed AA, Hassan AM, Weis JA, et al. Physical activity among Somali men in Minnesota: barriers, facilitators, and recommendations. Am J Mens Health 2014;8:35-44.

87 Murray KE, Mohamed AS, Dawson DB, et al. Somali perspectives on physical activity: PhotoVoice to address barriers and resources in San Diego. Progress in Community Health Partnerships 2015;9:83-90.

88 Nguyen T-UN, Tran JH, Kagawa-Singer M, et al. A qualitative assessment of community-based breast health navigation services for Southeast Asian women in southern California: recommendations for developing a navigator training curriculum. Am J Public Health 2011;101:87-93.

89 Nicdao EG, Henley A, Peterson JC. 'your Blood is Sweet': The illness experience of southeast Asian Refugees with type 2 diabetes. Res Sociol Health Care 2016;34:63-84.

90 Saadi A, Bond BE, Percac-Lima S. Bosnian, Iraqi, and Somali refugee women speak: a comparative qualitative study of refugee health beliefs on preventive health and breast cancer screening. Womens Health Issues 2015;25:501-8.

91 Schlomann P, Hesler S, Fister S, et al. Mexican Immigrants' Perceptions About Changes in Diet, Physical Activity, Stress, and Health. Hisp HIth Care Int 2012;10:190-8.

92 Vamos CA, Lockhart E, Vázquez-Otero C, et al. Abnormal Pap tests among women living in a Hispanic migrant farmworker community: a narrative of health literacy. J Health Psychol 2018;23:1622-34. 